\title{
Using a Touch-Based, Computer-Assisted Learning System to Promote Literacy and Math Skills for Low-Income Preschoolers
}

\author{
Mark H. McManis \\ University of Texas at Austin, Austin, Texas, USA
}

mmcmanis@austin.utexas.edu

\author{
Lilla Dale McManis \\ Early Childhood Research Solutions, Austin, Texas, USA \\ Idmcmanis@earlychildhoodresearchsolutions.com
}

\begin{abstract}
The use of touch-based technologies by young children to improve academic skills has seen growth outpacing empirical evidence of its effectiveness. Due to the educational challenges lowincome children face, the stakes for providing instructional technology with demonstrated efficacy are high. The current work presents an empirical study of the use of a touch-based, computerassisted learning system by low-income preschoolers. A description of the system's design is provided with attention to young children's interaction with touch devices, learner engagement, and pedagogically-based delivery of academic content. Children in 18 low-income child-care preschool classrooms were assessed on literacy and math skills in the fall and again in the spring. Target children used the iStartSmart learning system throughout the academic year, while control children did not have access to the system. Compared to controls, children using the learning system made significant gains on external standardized measures of literacy and math. Children who spent more time using the system and those who reached the upper levels of skill understanding showed the strongest improvement in test scores. The findings contribute to the currently sparse literature by illuminating that for at-risk early learners, touch-based, computer-assisted instructional technology shows promise as an educational tool.
\end{abstract}

Keywords: computer-assisted, touch-based, instructional technology, literacy, math, preschool, student achievement, low-income

\section{(c) $(1)(9)$}

This article has been copyrighted by the Informing Science Institute on behalf of its authors. We license it to you under a Creative Commons AttributionNonCommercial 4.0 International License. When you copy and redistribute this paper in full or in part, you need to provide proper attribution to it to ensure that others can later locate this work (and to ensure that others do not accuse you of plagiarism). You may (and we encourage you to) adapt, remix, transform, and build upon the material for any non-commercial purposes. This license does not permit you to use this material for commercial purposes.

\section{Introduction}

Successfully placing instructional technology into early education settings is a complex endeavor driven by a higher-than-usual responsibility for developmental appropriateness and efficacy. Due to the sensitive age of early learners, particular care must be taken to ensure that interactions with technology provide an appropriate, meaningful, and enjoyable learning experience (e.g., Clements \& Sarama, 2003; Glaubke, 2007; National Association for the 
Education of Young Children \& Fred Rogers Center, 2012 [NAEYC \& FRC, 2012]). When technology is part of the educational experience for low-income preschool children at risk for academic failure due to poverty, the stakes are even more pronounced. Against the backdrop that the poorest children start kindergarten 20 months behind in reading and math compared to the highest-income children (Nores \& Barnett, 2014), programs have just a short amount of time to remediate gaps. They face the substantial challenge of making effective decisions about how to spend limited funds on technology (Simon, Nemeth, \& McManis, 2013).

The rapid adoption of technology by early childhood programs, including those serving children of poverty, indicates that while desktops and laptops are the most frequently used by children, touch-based devices are becoming more prevalent (e.g., Simon et al., 2013; Teaching Strategies, 2015). This is likely related to the appeal touch devices have for young children, who can more easily operate devices that respond to direct touch of the electronic display than keyboard and mouse-driven technology (e.g., Chiong \& Shuler, 2010; Hourcade, Bederson, Druin, \& Guimbretiére, 2004). However, this increased use is raising concern among researchers and stakeholders that evidence of the efficacy of touch technology and its accompanying learning software is lacking (e.g., Guernsey, Levine, Chiong, \& Severns, 2012; NAEYC \& FRC, 2012; Shuler, 2012; Vaala, Ly, \& Levine, 2015).

More than three decades of literature show the positive outcomes in literacy and math for young children using older technologies; namely mouse- and keyboard-driven computers (see reviews by Glaubke, 2007; McCarrick \& Xiaoming, 2007; Penuel et al., 2009). Conversely, there is limited empirical research on children's learning outcomes in these skill areas using newer, touchbased technologies. This is particularly the case for devices designed with interactive adaptive responsiveness with content presented as computer-assisted instruction (CAI). We do know such learning is greatly enhanced when scaffolding, feedback, and elicited explanations and examples are present (e.g., Baroody, Eiland, Purpura, \& Reid, 2013).

We also know that despite technology quickly making its way into early childhood classrooms, there is mounting evidence of a 'digital divide' marked by less equity and access for low-income children (in education settings, those eligible for child-care subsidies or free and reduced lunch) compared to their higher-income peers, which spans their homes, early education settings, and communities (e.g., NAEYC \& FRC, 2012; Rideout \& Katz, 2016). Compounding matters, when low-income children do use technology, it is more likely to be passive consumption, which does not support high-quality learning (e.g., Daugherty, Dossani, Johnson, \& Wright, 2014; NAEYC $\&$ FRC, 2012). Efforts to reverse this trend and move toward supporting interactions with technology that are more conducive to learning for low-income children could be of value.

The purpose of this article is to help address the lack of empirical research on instructional technology for preparing at-risk early learners for formal schooling. We report an empirical study that examined the use of a touch-based, computer-assisted learning system and literacy and math performance for low-income preschoolers. The paper is organized into the following sections: study context, methods, results, discussion, conclusions, and further directions.

\section{Study Context}

In this section we first consider the literature on young children's ability to operate and learn while using touch devices, and then on the achievement gap and instructional experiences of young children of poverty. This is followed by a description of the design and development of iStartSmart ${ }^{\circledR}$, the specific educational application for early learners used in the study. 


\section{Young Children Using and Learning with Touch Technology}

Evidence is emerging that when young children do have access to newer touchscreen technologies, the tactile and directly-responsive nature of touch allows them to interact with devices easily and accurately (e.g., Beschorner \& Hutchison, 2013; Chiong \& Shuler, 2010; M. Cohen, Hadley, \& Frank, 2011; L. D. McManis \& Gunnewig, 2012; Neumann \& Neumann, 2014). They are freed from the fine-motor skills required to operate a mouse, which for young children are a substantial impediment (Hourcade et al., 2004). Research shows that while 4- to 7-year-olds had some initial trouble with turning on touch devices, swiping, tapping icons, and exiting, they quickly mastered these after playing with the devices a few times (Chiong \& Shuler, 2010). A national project found that touchscreen tablets provided easy access and supported both immediate and extended engagement. Young children interacted with them in ways similar to other non-technology settings, such as exploring, touching, repeating, trial and error, and working to make things happen (M. Cohen et al., 2011).

While there is an overall lack of empirical evidence to support the use of touch technology in early education for the learning of specific content and skills, some promising findings are beginning to emerge. For example, studies with kindergarteners found improved standardized test scores in literacy associated with lessons on a touch-based Interactive Whiteboard (IWB) (Kent, 2004), and significant gains compared to a non-intervention group in mathematical representation and fractions with content delivered through this device (Goodwin, 2008). A more recent study of content presented on an IWB with low-income preschoolers showed children made significant gains on standardized assessments in literacy for print knowledge, phonological awareness, and emergent writing and in math for counting, operations, and shapes from fall to spring (L. D. McManis, Gunnewig, \& McManis, 2010). A home-based study with iPod touch devices and PBS-created content for 3 to 7 -year-olds found that children made significant gains in vocabulary and phonological awareness, with children ages 3 to 5 making the most improvement (Chiong \& Shuler, 2010). Finally, a recently published report on a national math project showed that preschool children in classrooms using both videos and digital games on IWBs and laptops scored significantly higher on counting, numeral recognition, shapes, and patterning compared to controls (Pasnik \& Llorente, 2013).

Although the availability of early learning software for touch devices has occurred rapidly and is extensive, there has been inadequate attention to its developmental appropriateness or efficacy. A recent analyses of the most popular and expert-awarded language and literacy apps (small, specialized software applications) for early learners found that, in app stores or on the developer websites, only a quarter of the accompanying information mentioned a child development, education, or literacy expert involved in the development, and less than a third indicated an underlying educational curriculum or philosophy. Testing of any type was rare, with only a quarter referencing research testing. Usability or appeal testing was mentioned substantially more frequently than testing for learning efficacy (Vaala et al., 2015).

This appears to be in spite of the call to action for such research from many educators, researchers, and policy makers (e.g., Guernsey et al., 2012; NAEYC \& FRC, 2012; Shuler, 2012; Vaala et al., 2015). One such example is the widely disseminated joint position statement on technology and interactive media in early childhood programs published by the National Association for the Education of Young Children and the Fred Rogers Center for Early Learning and Children's Media (2012). Drawing on a comprehensive review of the literature, the committee that led this initiative concluded that children's cognitive abilities can be enhanced when technology is used appropriately, but qualified it with the need for additional research to verify the positive effects of technology tools on children's language/literacy and logical/mathematical understanding. So while touch-based technology use is increasing for young children and some preliminary empiri- 
cal results on academic learning outcomes exist, an established body of research has yet to fully develop.

\section{The Achievement Gap and Instruction of Low-Income Children}

Twenty-five percent of very young children in the United States live in poverty, and doing so before the age of six puts them at increased risk for educational deficits compared to their more affluent peers (Mattingly, Johnson, \& Schaefer, 2011). Low-income children are less likely to develop into mature readers compared to their middle-income peers (Burkam, Ready, Lee, \& LoGerfo, 2004). There are substantial gaps in mathematics as well, with young low-income children entering kindergarten far behind their middle-income peers on tasks assessing counting skills, knowledge of number relations, and number operations (Jordan, Kaplan, Locuniak, \& Ramineni, 2007; Jordan, Kaplan, Nabors-Oláh, \& Locuniak, 2006).

Overall, preschool programs spend relatively little time on literacy and math instruction. A review of several large-scale longitudinal studies, primarily of public school prekindergarten classrooms, showed that young children spent just $20 \%$ of the day engaged in language and literacy activities and 6\% in math activities (Hamre \& Pianta, 2007). Yet children in the publicly-funded options of Head Start and public school Pre-K are still likely getting a better experience in general compared to children attending child-care centers. In the latter, teachers are frequently nondegreed, which may be related to the fact that currently 17 U.S. states do not require lead teachers in child-care centers to have even have a high school diploma and 14 require only a high school diploma or GED (NACCRRA, 2013). Teachers in child-care also participate less in ongoing professional development (e.g., Barnett \& Frede, 2010). Teachers both being degreed and actively participating in professional development has been found to make a substantial difference for their students' academic school readiness, typified by competency in foundational literacy and math skills needed to be successful when beginning formal schooling (e.g., Barnett \& Frede, 2010; Bueno, Darling-Hammond, \& Gonzales, 2010).

The initial empirical evidence on young children's capacity for learning through touch technology combined with the current deficits in instruction for low-income preschoolers sets the stage to further investigate the degree to which literacy and math skills can be taught via instructional technology. We turn next to an overview of the principles guiding the design and development of the touch-based, computer-assisted instructional technology used in this study.

\section{Design and Development of the iStartSmart (iSS) Learning System}

This section expands on the developmental appropriateness of touch technology and addresses the key considerations of child engagement, child friendliness, and appropriate content and delivery as they were used for the design and development of the iStartSmart.

\section{Goodness-of-fit: The developmental appropriateness of touch technology}

Developmental appropriateness refers to instructional techniques and approaches that consider the age and individual needs of early learners. That young children have a need to physically interact with their world to learn and develop derives most notably from child development, particularly cognitive theorists Jean Piaget and Jerome Bruner. Their learning principles offer widely accepted and utilized guidance for the educational settings and experiences of young children. Piagetian constructs about using technology are framed most regularly as supporting construction of knowledge (e.g., Gillani, 2003; Lourenço, 2012). Using touch technology maps onto Piaget's sensorimotor stage of learning where a child begins the process of learning using the combination of 
senses and motor skills to understand his/her environment. The transition to the next stage of preoperational thought as children become older toddlers and preschoolers is at play as they explore interactive touch technology for cause and effect as well as an arena for the blossoming of symbolic thought.

In an interview, Sandra Calvert, Professor of Psychology and Director of the Children's Digital Media Center at Georgetown University, stated that from a developmental perspective, touchbased device-interfaces match how young children already interact with the world. Calvert points to differing levels of understanding and communication that develop as a child matures according to Bruner's modes of representation about how children gain information and construct knowledge (e.g., Subrahmanyam \& Greenfield, 2008). The first mode is enactive representation, which is action-based. This involves the child using his/her body to communicate and encompasses the main way children communicate during their first years. From here, children move next to iconic (picture-based), and then to symbolic (language-based) representations and modes of communication. Calvert maintains that touching and sweeping on a touchscreen device fits "exactly in with how very young children think" (Baute, 2010). Others agree that because sensory input is a primary mode of learning for young children, the interactive nature of touch devices promotes learning readiness by representing visual and tactile experiences that are of high interest and motivating (DeCurtis \& Ferrer, 2011). A recent literature review by Neumann and Neumann (2014) on touch-based tablets and literacy highlights that the simple tactile nature of the interface and the ability to use fingers to operate these devices expedites the use of the applications and software by preschoolers.

\section{Designing for early learners: Key considerations when developing software}

A learner's experience is influenced by the software as a function of how the device, affordances, and content merge and blend. The iSS software was designed to be delivered on a touchscreen device and with foremost attention to engaging the child in learning, child-friendliness, and providing appropriate content.

Child Engagement: Setting the learning in contexts that represent environments of interest to children is something many developers do quite well. It is important, though, to ensure enough activities/assets are available for the level of continued use necessary for learning to occur. Most apps, for example, are downloaded and played only once or twice (Localystics, 2011), a duration that would greatly reduce the potential for learning. With this in mind, the iSS contains games in 18 literacy and math skill areas, organized into five skill families (see Table 1).

Table 1. Skill families and skill areas in the iStartSmart

\begin{tabular}{|l|l|l|l|l|}
\hline $\begin{array}{l}\text { Phonological } \\
\text { Awareness }\end{array}$ & $\begin{array}{l}\text { Alphabet } \\
\text { Knowledge }\end{array}$ & $\begin{array}{l}\text { Language } \\
\text { Development }\end{array}$ & $\begin{array}{l}\text { Logic and } \\
\text { Reasoning }\end{array}$ & $\begin{array}{l}\text { Numeric } \\
\text { Operations }\end{array}$ \\
\hline $\begin{array}{l}\text { Sentence } \\
\text { Segmenting }\end{array}$ & $\begin{array}{l}\text { Letter } \\
\text { Recognition }\end{array}$ & $\begin{array}{l}\text { Language } \\
\text { Vocabulary }\end{array}$ & Common Shapes & $\begin{array}{l}\text { Counting } \\
\text { Foundations }\end{array}$ \\
\hline Initial Sounds & & Spatial Skills & Sorting & $\begin{array}{l}\text { Numeral } \\
\text { Recognition }\end{array}$ \\
\hline $\begin{array}{l}\text { Blending } \\
\text { Compound Words }\end{array}$ & & Measurement & Patterning & $\begin{array}{l}\text { Sequence } \\
\text { Counting }\end{array}$ \\
\hline $\begin{array}{l}\text { Segmenting Com- } \\
\text { pound Words }\end{array}$ & & & & Objects In A Set \\
\hline Onset Rime & & & & Addition \\
\hline & & & & Subtraction \\
\hline
\end{tabular}


Another central area of engagement consideration has to do with excessive use of elements such as 'hot-spots', or areas on or around a graphic, object, or text that activate a function when touched/selected. Hot-spots are prevalent in software for young children and have been found to distract the child from the learning path (Chiong, Ree, Takeuchi, \& Erickson, 2012) or be irrelevant to the learning purpose (Vaala et al., 2015). To mitigate this effect, the iSS employs a response-action sequence directly connected to the skill being taught.

Child-Friendly: Even though young children are fast learners of touch inputs, it is imperative that the interface matches the motor skills preschoolers possess (Chiong \& Shuler, 2010). Therefore the design of the iSS interface followed recommendations for large icon size, expanding the target areas around the icons, and minimizing swiping with the responses being tap or pull/push oriented. Non-readers are supported by audio and visual tutorials presented prior to playing and verbal feedback from animated characters during gameplay. These modality supports are incorporated into the games following recommendations for design to support multi-modality learning (Sluis et al., 2004). Young children also need multiple opportunities for success. The feedback in the system uses a snap-in response to correct, addition and reduction of response options, upward and downward scaffolding of difficulty, and a teacher mode to allow guided play with a child without the responses determining progression.

The design of the system draws heavily on the application of Vygotsky's learning theory for educational settings to mesh with preschool children's zone of proximal learning (the range of tasks one can perform with assistance but not independently) and the use of scaffolding (support given for learning based on one's specific learning needs) (Lourenço, 2012). The software matches the child's abilities and moves with the child, a technique frequently called "scaffolding," though also referred to as "leveling." The scaffolding was built on elements including breaking down the skills and information to be learned into small units, monitoring children's work closely and consistently in real time, and providing feedback and encouragement (reinforcement). Each of these supports autonomous use of the system, a key affordance of CAI. Even so, CAI for young children should not happen in a vacuum. As does the iSS, a system needs built-in progressmonitoring that informs teachers of children's accomplishments and facilitates their instructional support. This is important given that, due to under-developed metacognition, young children can have a meaningful experience and still have difficulty determining whether and what they have learned (Schneider, 2008).

Appropriate Content: Researchers, policymakers, and educators all stress the importance of implementing early interventions in the academic areas of literacy and math, particularly for underresourced children of poverty (e.g., Karoly, Kilburn, \& Cannon, 2005; Reynolds, Temple, Ou, Arteaga, \& White, 2011). The basic cognitive and academic skills in which children must acquire competency in order to be successful in formal school are now well established (e.g., National Early Literacy Panel, 2008; National Research Council Committee on Early Childhood Mathematics, 2009). Early literacy skills developed before age five have a clear and consistently strong relationship with later conventional reading and writing skills. Six areas representing early literacy skills have strong predictive relationships with later literacy, maintaining their predictive power even when IQ or socioeconomic status (SES) are accounted for: alphabet knowledge, phonological awareness, phonological memory, rapid automatic naming of letters/digits, and writing/writing name.

The National Research Council Committee on Early Childhood Mathematics (2009) found that virtually all young children have the capability to learn and gain competency in mathematics and that, well before the first grade, children can learn the ideas and skills necessary to support subsequent and more complex mathematical understanding. However, young children's mathematics instruction has been found to be substantially under-taught in early education, which appears to be exacerbated by a high level of discomfort around teaching math felt by many early childhood 
teachers (e.g., Hamre \& Pianta, 2007; National Research Council Committee on Early Childhood Mathematics, 2009). The Committee's consensus is that two main areas of mathematics are particularly important for young children: (1) number, which includes whole number, operations, and relations and (2) geometry, spatial thinking, and measurement.

As these findings and recommendations indicate, literacy and math are comprised of many skills. In developing the iSS system, the 18 literacy and math skills were organized into five skill families based on findings and recommendations from these two committees and on accepted early childhood education pedagogy. A previous principal component analysis investigated the statistical underpinnings of the content and its organization when delivered to learners (P. W. McManis $\&$ McManis, 2016). Six components (factors) emerged based on theoretical support and having eigenvalues greater than one. Four of the six matched directly with their respective iSS Skill Families: Phonological Awareness, Logic and Reasoning, Language Development, and Alphabet Knowledge. The skills in the Numeric Operations Family were distributed across two components, but in a meaningful way. Counting foundations and numeral recognition skills loaded together and primarily represent identification, making them somewhat distinct from the operations skills which loaded together. However, as all the skills in these two components tap mathematical concepts, they fit together well in the Numeric Operations Family for presentation to the learner as relevant; particularly as counting foundations and numeral recognition skills are presented to children prior to the operations skills when they play the games.

In summary, given that touch devices fit well with how young children engage physically with their environment, best practices dictate that affordances in the interface and software be based on developmentally-appropriate practices to reflect how young children respond and learn. When a system has the goal of improving specific skills such as literacy and math, adequate attention given to the nature of the content and a systematic, logical presentation can considerably facilitate the user having a pedagogically sound learning experience.

\section{Objectives of the Study}

Designing and developing well-conceived touch-based, computer-assisted instructional technology is essential. Of equal importance is determining the extent to which children's use of such instructional technology is related to learning the skills intended. This is the overarching goal of the present study. The following research question and hypotheses were addressed specifically around learning outcomes. The research question is, "Can using computer-assisted, touch-based instructional technology improve literacy and math performance for low-income preschoolers?"

- Hypothesis 1: Low-income preschoolers who use the iSS will show stronger gains in standardized literacy and math assessment scores compared to their peers who do not have access to the iSS.

- Hypothesis 2: For low-income preschoolers who use the iSS, there will be a relationship between more time spent playing the literacy and math games and improvements on standardized literacy and math assessment scores.

- Hypothesis 3: For low-income preschoolers who use the iSS, there will be a relationship between higher levels achieved when playing the literacy and math games and higher standardized literacy and math assessment scores.

\section{Methods}

\section{Study Design}

We used a mixed design analysis of variance (ANOVA) to assess the contribution of the learning system to literacy and math performance in this quantitative, quasi-experimental study. Two 
groups, one using the iSS and the other not, were assessed in the fall and spring. A large nonprofit child-care umbrella organization supplied a list of programs, both with and without the iStartSmart, to be used for recruitment. The study was exempted from full Board review by the organization due to the study's use of established learning methods in a regular classroom setting.

\section{Participants}

Eighteen child-care preschool classrooms serving low-income children in an urban setting participated during the 2011-2012 school year. There were nine target and nine control classrooms. The number of classrooms was selected to provide an adequate representation of the range in curricula, materials, and philosophies present in independently-operated child-care programs. The target classrooms had previously purchased an iSS learning system and the control classrooms had no iSS systems.

A subset of children whose home language was English was randomly selected from each classroom for pre- and post-testing. Random selection was used to reduce the risk of bias in the sample. There were 79 children recruited from the target classrooms and 81 recruited from the control classrooms in the fall. At the time of post-testing, 16 of the children in the target classrooms and 11 children in the control classrooms had left their preschool. An additional eight children were excluded from the target group due to spending too little time on the iSS system to move beyond the tutorial stage, where all children begin for all skills. The final sample consisted of 55 children in the target group and 70 in the control group. Table 2 shows the ethnicity of the participants. Gender distribution within both groups was relatively even. In the target group 52.8\% were boys and $47.2 \%$ girls. In the control group $48.6 \%$ were boys and $51.4 \%$ girls.

\section{Table 2. Number of children by ethnicity in target and control groups}

\begin{tabular}{|lrr|}
\hline & Target & Control \\
\hline Asian & 2 & 0 \\
Black & 33 & 21 \\
Hispanic & 6 & 17 \\
White & 9 & 30 \\
Not Specified & 5 & 2 \\
\hline
\end{tabular}

\section{Procedures}

The pre- and post-testing was done individually with children at their child-care centers and outside the classroom. Children were administered one literacy and one math assessment in the fall and again in the spring, with approximately six months between assessments. These standardized assessments involved the assessor asking the child a question and the child indicating his/her response by pointing to a picture in a flip book for the majority of the questions or verbally for a few of the questions. Each assessment session took 30 minutes or less per child. The assessors were blind as to whether the children were in the target or control group.

No changes to instructional activities were made in the target or control classrooms as a part of this study. The iSS systems had been in the target classrooms for approximately one year before the study. Teachers were asked to encourage children to use the software for about 30 minutes per week based on work from a previous pilot study. Brief monthly site visits to target classrooms were made to download data from the computers and inquire if there were any issues with using the system. For the control classrooms, after the pre-testing and one reminder of upcoming posttesting, there was no contact until the spring. 


\section{Measures}

\section{Assessing academic skills}

Two standardized measures were used to determine children's skills in literacy and mathematics, both with demonstrated reliability and validity, and appropriate for preschool populations of various socioeconomic and ethnic backgrounds and program settings. The Test of Preschool Early Literacy (TOPEL) creates an Early Literacy Index (ELI) from print knowledge, phonological awareness, and definitional vocabulary subtests. The internal consistency reliability for the Index is .96 (print knowledge .95, phonological awareness .87, definitional vocabulary .94) (Lonigan, Wagner, Torgesen, \& Rashotte, 2007). The ELI score was used in this study. The Bracken School Readiness Assessment measures math concepts including numbers, counting, sizes, comparison, shapes, letter identification, and colors. The Bracken composite score, also called the Bracken School Readiness Index, has an internal consistency of .95 (Bracken, 2007). The Index score was used in this study.

\section{Use of the iStartSmart (iSS) learning system}

In this study, the device was a touchscreen desktop computer. The iSS software has games in 18 skill areas grouped into five families covering literacy and mathematics (see Table 1). The skill areas are scaffolded by difficulty into five levels: tutorial, emerging, developing, developed, and completed (skill maintenance). Each child begins each skill at the tutorial level. As children play, they move through the levels based on automated rules which determine each child's progression. The system provides automatic intervention and instruction based on the response provided by the child. Along with the amount of time spent in each skill area, the system maintains real-time progress data and also takes a snapshot of the level each child has attained three times a year (Oct. 15, Jan. 15, and Apr. 15). The April snapshot data of level attained and cumulative time spent in each of the 18 skills was used in the analyses for this study.

\section{Analyses}

A series of multivariate mixed-model analyses of variance (MANOVA) was used for the first hypothesis to determine whether target children made significantly greater gains over time on the external standardized literacy (TOPEL) and math (Bracken) assessments, relative to controls. Following up on the analysis of pre- to post group differences, a series of between-subjects ANOVAs and t-tests was carried out.

For the second hypothesis we computed correlation coefficients to show the relationship between time spent on the iSS and improvements in standardized assessment scores. Composite time-onskill measures were computed by summing the time spent on all skills, another for time spent on literacy skills, and again on math skills. An improvement score was computed as the difference between the post-test and pre-test scores for the TOPEL and Bracken.

Our analysis plan for the third hypothesis was to use independent samples t-tests to compare the performance on the external standardized assessments of children who reached the upper two levels (developed or completed) in the iSS, relative to those who did not. To examine the relationship between progress through the skill levels and the TOPEL and Bracken, three composite skill attainment scores were computed based on the skill levels recorded in the iSS at the final progress monitoring snapshot (April 15).

The Overall Attainment Score was based on the average level achieved across all 18 skills. To be considered Overall Developed, a child had an average level of developed/completed across all 18 skills. Children who did not yet have an average level of developed/completed across all 18 skills were categorized as Overall Developing. The Literacy Attainment Score was based on the aver- 
age level attained across the seven literacy skills and the Math Attainment Score was based on the average level attained across the 11 math skills. In a similar manner to determining Overall Developed or Developing, a child considered Literacy Developed or Math Developed had an average attained level of developed/completed across all literacy skills or all math skills; if this had not yet been reached, children were categorized as Literacy or Math Developing, respectively.

\section{Results}

To test our first hypothesis that children who used the iSS would show greater gains on standardized measures of literacy and math, pre-test and post-test data were available for 125 children (55 target, 70 control). A multivariate mixed between- and within-subject MANOVA was computed to assess differences in performance for the target versus control (between-subjects) experimental groups over time, from pre-test to post-test (within-subjects) for both the TOPEL and the Bracken (see Figure 1). There was a significant interaction between experimental group and pre-post test scores on the TOPEL $(F(1,123)=5.69 ; p=.02$; Pillai's Trace $=.044)$ and a marginally significant interaction between experimental group and pre-post test scores on the Bracken $(F(1,123)=$ $2.78 ; p=.10$; Pillai's Trace $=.022)$. There was also a significant increase in age-corrected standardized scores for all children on the TOPEL $(F(1,119)=39.92 ; p<.001)$ and the Bracken $(F(1$, $119)=14.62 ; p<.001)$ from pre-test to post-test, consistent with the academic nature of the prekindergarten year.

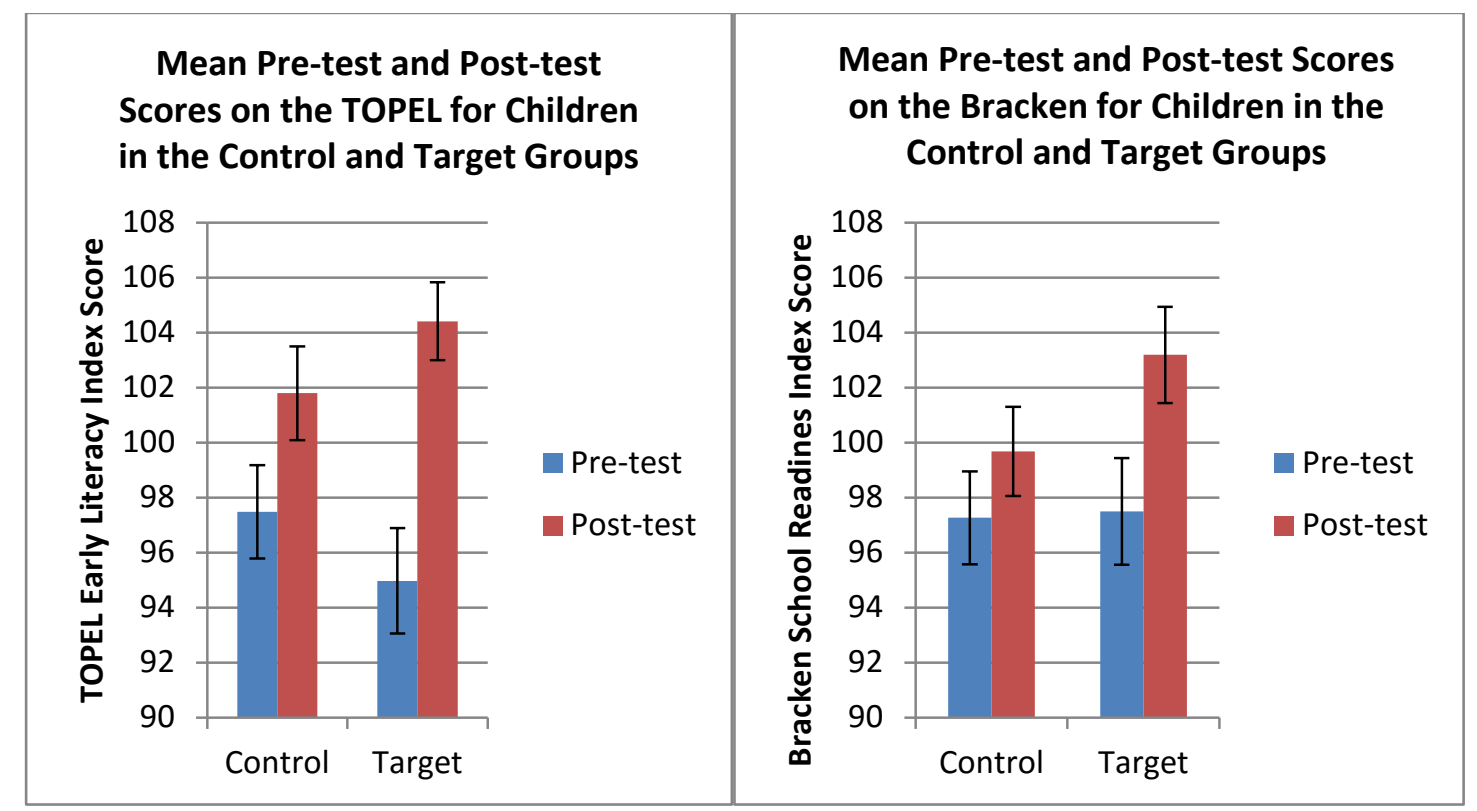

Figure 1. Mean and standard errors for control and target groups at pre-test and post-test for the TOPEL and Bracken.

There was no significant main effect or interaction of gender on the TOPEL or Bracken. To test for gender effects, gender was included in the model, along with experimental group, as betweensubjects variables with pre-post scores as a repeated measures variable. On the TOPEL, there was no significant main effect of gender $(F(1,121)=.02 ; p=.89)$ or interaction (gender * experimental group: $F(1,121)=.18 ; p=.67$; gender*experimental group*pre-post: $F(1,121)=.57 ; p=$ .45 ; Pillai's Trace $=.005)$. For the Bracken, there was no significant main effect of gender $(F(1$, $121)=.01 ; p=.93$ ) or interaction (gender*experimental group: $F(1,121)=.24 ; p=.63$; gender*experimental group*pre-post: $F(1,121)=.08 ; p=.77$; Pillai's Trace $=.001)$. 
There was no significant main effect or interaction of ethnicity on the TOPEL or Bracken. To test for ethnicity effects, it was included in the model, along with experimental group, as betweensubjects variables with pre-post scores as a repeated measures variable. Due to a small number of Asian children $(n=2)$ and some children whose ethnicity was not specified $(n=7)$, the analyses were done with three ethnic groups (Black, Hispanic, and White) with a total of 116 children. On the TOPEL, there was no significant main effect of ethnicity $(F(1,110)=2.03 ; p=.14)$ or interaction (ethnicity*experimental group: $F(1,110)=.55 ; p=.57$; ethnicity*experimental group*prepost: $F(1,110)=1.20 ; p=.31$; Pillai's Trace $=.021)$. For the Bracken, there was no significant main effect of ethnicity $(F(1,110)=2.02 ; p=.14)$ or interaction (ethnicity*experimental group: $F(1,110)=.24 ; p=.79$; gender*experimental group*pre-post: $F(1,110)=.97 ; p=.38$; Pillai's Trace $=.017)$.

As a follow-up analysis of the interaction between experimental groups from pre-test to post-test, t-tests were used to determine whether there was a significant difference between the target and control groups at pre-test on the standardized assessments. There was no significant difference between the target and control groups at pre-test for either the TOPEL $(t(123)=.98 ; p=.33)$ or the Bracken $(t(123)=-.09 ; p=.93)$. To test whether children who used the iSS would show greater improvement of literacy and math skills than their preschool peers who did not use the system from fall to spring, t-tests were calculated to determine whether the increase in standardized assessment scores was higher for those children who used the iSS compared to controls. A difference score (post-test minus pre-test) was computed for each child on the TOPEL and on the Bracken. Means and standard errors for these are shown in Figure 2. Independent samples t-tests on the difference between each child's pre-test and post-test scores showed that children using the system had significantly greater improvements in scores on the TOPEL $(t(123)=2.38 ; p<.01$ (one-tailed)) and Bracken $(t(123)=1.67 ; p=.05$ (one-tailed)) than control children (see Figure 2).

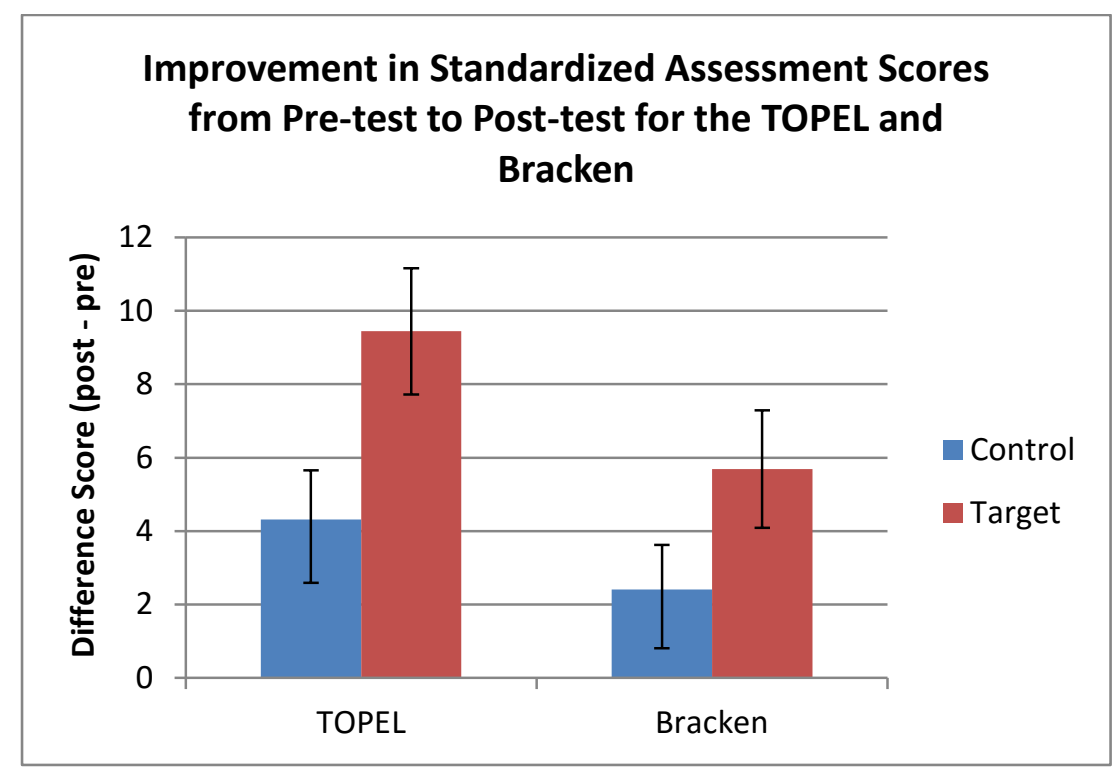

Figure 2. Mean improvement from pre-test to post-test for target and control groups for the TOPEL Early Learning Index and the Bracken School Readiness Index

Another way to look at the degree to which using the iSS was associated with improved standardized assessment scores is to compute effect sizes. Cohen's $\mathrm{d}$ for the between groups comparison of target versus control was calculated from the group means of the differences between pre-test and post-test scores and the pooled standard deviations, with the different group sizes taken into 
account (J. Cohen, 1992). The improvement in the TOPEL had an effect size $d=.46$, and for the Bracken the effect size was $d=.30$; both in the medium range.

We used the amount of time each target child spent on all skills to test the second hypothesis that there would be a positive relationship between time spent playing the iSS games and standardized assessment scores and to further explore the effects of the iSS on the pre-test and post-test scores. An improvement score was calculated as the difference in assessment scores from pre-test to post-test (post-test - pre-test). The composite time spent overall was calculated as the sum of the time spent (in minutes) playing the games on the iSS (see Table 3). Using the composite time-ongames across all literacy skill games, there was a statistically significant positive relationship between the amount of time spent and an improvement on the TOPEL $(r=.26, n=55, p=.03$ (onetailed)). There was a statistically significant positive relationship between the composite time-ongames across all math skill games and an improvement on the Bracken $(r=.24, n=55, p=.04$ (one-tailed)). However, there was no relationship between the total time spent across all skill games and either the TOPEL $(r=.15, n=55, p=.26)$ or the Bracken $(r=.22, n=55, p=.11)$, respectively.

Table 3. Number of children who reached the developed and developing level on composite scores and mean amount of time spent playing iStartSmart games

\begin{tabular}{|lcccc|}
\hline & \multicolumn{2}{c}{ Developed } & \multicolumn{2}{c|}{ Developing } \\
\hline & $\mathrm{N}$ & Minutes (SD) & $\mathrm{N}$ & Minutes (SD) \\
\hline Overall & 21 & $864(287)$ & 34 & $671(249)$ \\
Literacy & 21 & $341(124)$ & 34 & $291(133)$ \\
Math & 25 & $492(204)$ & 30 & $387(191)$ \\
\hline
\end{tabular}

To test the third hypothesis that, within the target group, reaching higher levels of the iSS would be related to higher literacy and math standardized assessment scores, t-tests were used to determine whether the increase in scores was greater for those children who reached the upper levels of skill development. Using composite scores, target children in the Developed and Developing levels (see Table 3) were compared on the standardized assessments. As can be seen in Figure 3, children who were in the Overall Developed group across all 18 skills showed significantly more improvement than children who were in the Overall Developing group from pre-test to post-test on the TOPEL $(t(53)=1.89 ; p=.03$ (one-tailed)) and on the Bracken $(t(53)=1.65 ; p=.05$ (onetailed)).

Although there was no significant relationship between literacy composite skill level and improvement from pre-test to post-test on the TOPEL, children who were Literacy Developed had significantly higher scores on the TOPEL at post-test compared to children who were Literacy Developing $(t(53)=1.78 ; p=.04)$. Similarly, while there was no significant relationship between math composite skill level and improvement pre-test to post-test on the Bracken, children who were Math Developed had significantly higher scores at post-test compared to children who were Math Developing $(t(53)=2.01 ; p=.025)$. 


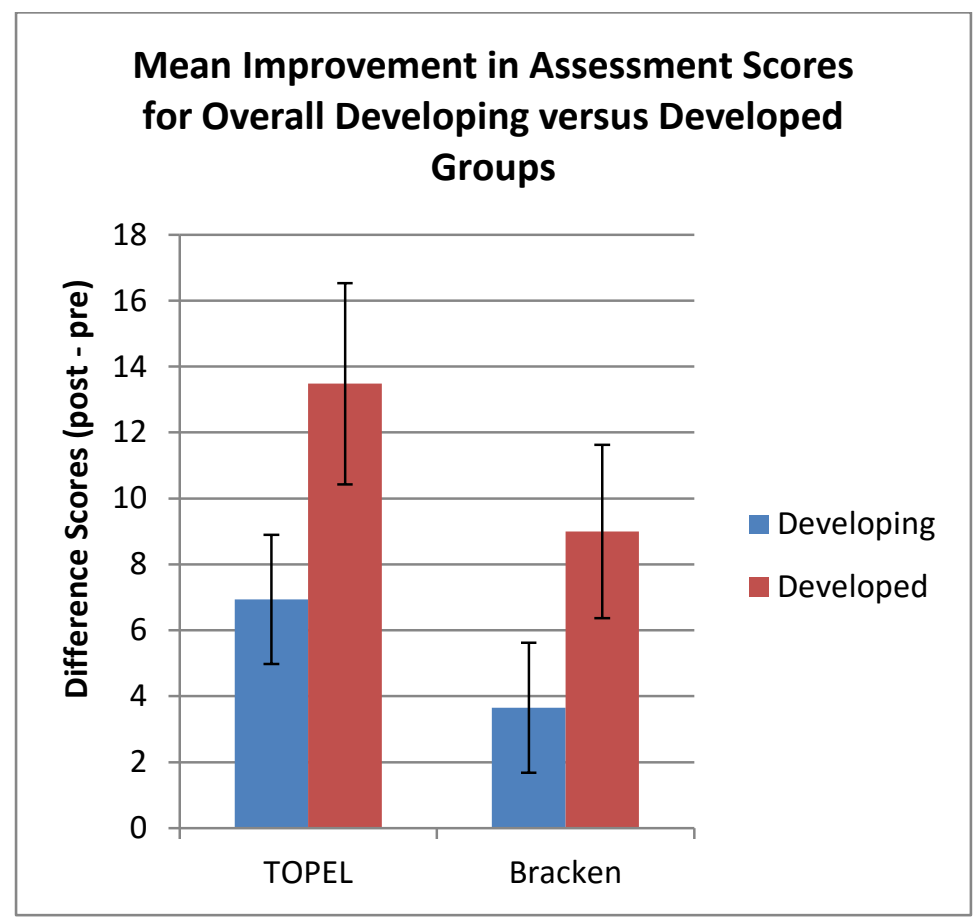

Figure 3. Comparison of iStartSmart composite attainment level in literacy and math skills for developing and developed levels

\section{Discussion}

This study investigated whether using computer-assisted, touch-based instructional technology could improve literacy and math performance for low-income children. Our hypothesis that lowincome preschoolers who use the iStartSmart (iSS) learning system would show stronger gains in literacy and math scores compared to controls was supported. Children using the iSS showed significant improvement in literacy and math on external standardized measures compared to children who did not use the system. The finding that target children made significant gains in math is particularly encouraging as math is under-taught in early childhood classrooms (e.g., Hamre \& Pianta, 2007). The significant gains in literacy are also still of considerable value because even though there is generally more focus on literacy than math in early education, literacy is also only taught for a small portion of the day in the typical prekindergarten classroom (e.g., Hamre \& Pianta, 2007).

In this low-income sample, although the control and target groups were not balanced on ethnicity (see Table 2), there was no significant interaction for ethnicity and group. Research suggests that what fundamentally drives the achievement gap is poverty rather than ethnicity (e.g., Duncan \& Magnuson, 2005; Lacour \& Tissington, 2011). There is considerable research showing that it is the accompanying shortage of resources for children, such as a less stimulating environment, rather than ethnicity that primarily contributes to lower academic performance (Duncan \& Magnuson, 2005). While attending preschool has the potential to provide a stimulating environment, low-income children typically attend preschools with lower quality. A contributing factor to this lower quality is non-degreed teachers who are less likely to be skilled in teaching literacy and math than degreed teachers (e.g., Barnett \& Frede, 2010; Bueno et al., 2010; NACCRRA, 2013). Relying on traditional materials may not be of much help either, as few early education math or reading curricula possess robust empirical support (Whitehurst, 2003). The results found in this 
study suggest that the computer-assisted nature of the iSS could offer some relief from challenges that currently impede sound teaching of literacy and math skills to low-income students.

Even were empirical evidence available that instructional technology could help children gain academic school readiness skills, some members of the early childhood field, as well as parents, have concerns about a "technology take-over" at the expense of other activities and areas of learning (e.g., Levin, 2011; Linn, Almon, \& Levin, 2012). In the current study, the children using the iSS did so for a small amount of time weekly, approximately half an hour on average (see Table 3). In such a scenario, children would still have most of their time available for teacher-led instruction as well as other kinds of experiences such as social interaction, art and music, dramatic play, free play, and physical activity.

However, it is worth pointing out that observations from several notable and large longitudinal studies reveal the average preschooler spent $42 \%$ of his/her time not engaged in the instructional and learning activities of language and literacy, math, science, social studies, aesthetics (art and music), and fine and gross motor (like coloring or playing with blocks) A third of this noninstructional time was spent in activities such as transitioning, waiting in line, meals, or washing hands. In these studies, if a teacher engaged the students in a learning activity during these times, such as reading a book during snack or reciting a poem during transition, this was coded as instructional time, but few preschool teachers did so (Hamre \& Pianta, 2007).

It may be somewhat difficult to determine exactly why instructional activities are infrequent, but the young age of preschool children does require active, consistent monitoring by an adult. This could be one reason as well that when instruction does occur in preschool, it is much more likely to be large group or free choice/centers (at about 28\% each) compared to small group and individual instruction (at about 6\% each) (Early et al., 2005). While there is value in large group instruction, it is not as conducive to differentiated or individualized instruction, which is especially needed by children struggling with learning concepts. The benefit of computer-assisted instruction, in general, for individualizing instruction for young learners is becoming well-established (e.g., Ayvacı \& Devecioğlu, 2010; Vernadakis, Avgerinos, Tsitskari, \& Zachopoulou, 2005).

Neither the iSS specifically, nor instructional technology in general, is a panacea. However, if its efficacy is demonstrated, then using learning systems like the iSS may offer children an opportunity for instruction that otherwise might not be present, either because their teachers are not skilled enough and have inadequate traditional teaching materials or because enough time is simply not available to busy teachers responsible for monitoring a large number of children while also trying to meet each individual child's instructional needs every day.

Our second hypothesis, that the greater the amount of time children in the target group spent playing the iSS games would be related to higher literacy and math scores on standardized assessments, was supported. Adequate time-on-task is a key indicator that children are engaging with the content presented in the games. However, it is important not to assume that they have learned during this time. Reliable and valid external assessments, such as the TOPEL and Bracken that tap the underlying nature of the skills taught in the iSS, help illuminate the degree of improvement that occurred in relationship to time playing the literacy and math games. Additionally, a key component to indicate engagement is to have scaffolded levels that represent the degree to which a child has achieved adequate understanding of a skill. Our third hypothesis, that children who reached the upper levels in the iSS would have higher standardized assessment scores, was supported. At the end of the study, target children who had successfully demonstrated understanding of enough of the skills to be considered Developed (an average level of developed/completed across all 18 skills) showed stronger improvement on literacy and math scores from fall to spring than those who were Developing (not having attained an average level of developed/completed across all 18 skills). Although this fall to spring improvement did not hold 
when looking just within literacy or math, it did hold for showing that Literacy Developed and Math Developed children had significantly higher post-test literacy and math assessment scores, respectively.

The amount and type of content to which young learners have access is of interest as literacy and math are overarching areas made up of a number of essential core skills in which young children need to acquire competency to be ready for formal school. Ensuring these areas are represented when selecting instructional technology for their classrooms can be a daunting job for teachers. For example, as of January 2015 the Apple App Store housed 80,000 apps labeled "educational", which for the most part were untested and unregulated (Hirsh-Pasek et al., 2015). Apps for young children continue to be among the most popular, with a 2012 analysis of Apple's iTunes store finding almost three-quarters of top-selling paid apps in the Education category targeted preschool or elementary children, a rise from 50\% three years previously (Shuler, 2012).

Many apps are "single-shot", having a narrow purpose and little substantive content for children. Teachers would therefore need to amass a large library of these, and subsequently face several challenges including accumulating costs, evaluating quality, assembling a systematic program for the children, and then manually monitoring children's learning, as most apps do not include progress-monitoring features (L. D. McManis \& Gunnewig, 2012). Of these, the challenge with perhaps the most difficulty for teachers may be evaluating quality to determine that efficacy evidence supports the potential to improve their students' learning. For example, a well-designed study investigating literacy and math achievement associated with using touch tablets (iPads) for kindergartners through second graders found only a suggestion of improvement for target children compared to controls (Bebell \& Pedulla, 2015). The tablets were loaded with almost two dozen separate literacy and math apps. The researchers note in further work that more attention to measuring children's use of specific apps might have an impact on findings. However, they do not address another possible contributor to a lack of significant improvement for the target children. Determining app quality was not part of the study's design, but rather the classroom teachers evaluated and selected them. We might postulate that even degreed teachers may sometimes lack the capability to do this well on their own.

To account for the breadth and depth needed to provide adequate opportunity for children to reach competence in literacy and math during the year before kindergarten, using instructional technology for small periods of time over the course of the year would be more developmentally appropriate than large chunks of time. The results show the children made the gains in literacy and math standardized assessment scores spending a modest amount of time weekly using the iSS system. This is also a major reason why the study took place over approximately 24 weeks ( 6 calendar months) of instruction. Additionally, this allowed the study to run well beyond the minimum 12 weeks recommended to ensure a reliable measure of instructional technology implementation (Cheung \& Slavin, 2013). The medium range effect sizes found for the between-subjects analyses lend support for the case that using the iSS has educational relevance. The effect sizes found in this study are in line with other research (see reviews by Cheung \& Slavin, 2013; Torgerson \& Zhu, 2004), though it should be noted that most studies included in such large reviews or meta-analyses of computer-assisted instruction in literacy and math are with early elementary children, as there are as yet few studies with preschoolers. We note, then, that the results of this empirical study show significantly higher standardized test scores for children using the iSS compared to controls, significantly higher standardized test scores for children who used the iSS more, and effect sizes comparable to similar studies.

\section{Limitations}

The following limitations of the study are noted. The classrooms could not be randomly assigned to target or control condition in this particular study. We sought to reduce the chance of initial 
selection bias by randomly selecting the children within the classrooms for the standardized assessments. We feel this was sufficiently addressed as children in the target and control groups were not statistically different from one another at pre-test on either the literacy or math standardized assessments. The sample size was modest, with the final sample size more so related primarily to attrition when children no longer attended the child-care centers in the spring for posttesting. The amount of movement in and out of child-care programs interspersed with relative care is known to be substantial for low-income children (e.g., Adams \& Rohacek, 2010). While attrition appeared larger for the target group, based on not finding differences at pre-test, we believe this was random.

We cannot completely rule out other explanations for the significant improvements found for the target children. We were interested in conducting the study in a natural setting and avoiding rigid implementation requirements to enhance generalizability, as well as being sensitive to not overburdening under-resourced teachers. However, the sample was comprised of low-income children attending preschool in for-profit child-care centers in a large urban metropolitan area, therefore generalizing to other socioeconomic groups and settings would need to take this into account. We were aware of the wide variability in instructional experiences and time spent on academic areas that is more pronounced in early childhood education than once children enter the K-12 system (e.g., Hamre \& Pianta, 2007). The direct instructional experience we examined was provided to target children through the iSS rather than the teacher, thereby reducing teacher/classroom and/or program effects. Additionally, we included classrooms in several child-care centers to reduce the possibility of these influences (e.g., Cheung \& Slavin, 2013), although we did not do so statistically. We were not able to know or control the degree to which children may have received instruction in similar literacy and math content outside of the iSS. We cannot definitively attribute improvement on the assessments to the computerized presentation of the literacy and math content. It is possible that any method of presentation that provided more exposure would have had the same effect.

\section{Conclusions}

This study contributes to the call for building a body of empirical evidence on the efficacy of newer touch-based and computer-assisted instructional technology applications to improve young children's educational skills (e.g., Guernsey et al., 2012; Shuler, 2012; Vaala et al., 2015). The findings of this study suggest that young low-income children have the potential to benefit from touch-based, computer-assisted instructional technology in the areas of literacy and math skills. The significant increases in standardized assessment scores in literacy and math found for lowincome children using the iStartSmart (iSS) Learning System were achieved during a moderate amount of gameplay time, about a half hour weekly over a six month period. Results also show that reaching the upper levels in the system was related to higher scores on literacy and math assessments.

The inclusion of such technology in early childhood classrooms may be useful as one piece in the large task of promoting literacy and math skills for low-income children who face challenges, such as a substantial academic achievement gap at entry to kindergarten, a digital divide marked by less access to and learning with technology, and a lower-quality preschool experience. Instructional technology should have, and be able to demonstrate, a strong focus on educational theory, principles, and pedagogy (e.g., Hirsh-Pasek et al., 2015; L. D. McManis \& Gunnewig, 2012). Underlying this is the importance and responsibility of developers to carefully consider interfaces and content based on research about how and what skills young children need to learn when designing learning software to support academic preparation for formal schooling. 


\section{Further Directions}

This initial study lays the groundwork to replicate the findings and to extend generalizability to other early childhood education settings such as Head Start and public school Pre-K. Another area of interest is in further correlating the skills and levels in the iSS with additional standardized school-readiness literacy and math assessments. It is not feasible for the majority of early childhood teachers to access and become trained to administer such assessments. Additional findings similar to those of the current study, could give teachers and program administrators increased confidence that when their students reach the developed levels in the iSS, they have achieved understanding of key skills.

\section{References}

Adams, G., \& Rohacek, M. (2010, October). Child care instability: Definitions, context, and policy implications. In Workshop Session C2 (Vol. 10, p. 45). Retrieved from http://www.urban.org/sites/default/files/alfresco/publication-pdfs/412278-Child-Care-InstabilityDefinitions-Context-and-Policy-Implications.PDF

Ayvaci, H. S., \& Devecioğlu, Y. (2010). Computer-assisted instruction to teach concepts in pre-school education. Procedia-Social and Behavioral Sciences, 2(2), 2083-2087. Retrieved from http://www.sciencedirect.com/science/article/pii/S1877042810003253

Barnett, W. S., \& Frede, E. (2010). The promise of preschool: Why we need early education for all. American Educator, 34(1), 21-40. Retrieved from http://www.aft.org/sites/default/files/periodicals/BarnettFrede.pdf

Baroody, A. J., Eiland, M. D., Purpura, D. J., \& Reid, E. E. (2013). Can computer-assisted discovery learning foster first graders' fluency with the most basic addition combinations? American Educational Research Journal, 50(3), 533-573.

Baute, N. (2010, June 17). Is the iPad the next big toy for toddlers? The Star. Retrieved from http://www.thestar.com/life/health_wellness/2010/06/17/is_ipad the next big_toy for_toddlers.html

Bebell, D., \& Pedulla, J. (2015). A quantitative investigation into the impacts of 1:1 iPads on early learner's ELA and math achievement. Journal of Information Technology Education: Innovations in Practice, 14, 191-215. Retrieved from http://www.informingscience.org/Publications/2175

Beschorner, B., \& Hutchison, A. (2013). iPads as a literacy teaching tool in early childhood. International Journal of Education in Mathematics, Science and Technology, 1, 16-24. Retrieved from http://www.ijemst.net/article/view/5000036037/5000034956

Bracken, B. A. (2007). Bracken school readiness assessment (third edition). San Antonio, TX: Pearson.

Bueno, M., Darling-Hammond, L., \& Gonzales, D. (2010). A matter of degrees: Preparing teachers for the pre-k classroom. Washington, DC: Pew Center on the States. Retrieved from http://www.pewtrusts.org/ /media/legacy/uploadedfiles/wwwpewtrustsorg/reports/prek_education/pkneducationreformseriesfinalpdf.pdf

Burkam, D. T., Ready, D. D., Lee, V. E., \& LoGerfo, L. F. (2004). Social-class differences in summer learning between kindergarten and first grade: Model specification and estimation. Sociology of Education, 77(1), 1-31.

Cheung, A. C. K., \& Slavin, R. E. (2013). The effectiveness of educational technology applications on mathematics achievement in K-12 classrooms: A meta-analysis. Educational Research Review, 9(1), $88-113$.

Chiong, C., Ree, J., Takeuchi, L., \& Erickson, I. (2012). Print books vs. e-books: Comparing parent-child co-reading on print, basic, and enhanced e-book platforms. New York, NY: The Joan Ganz Cooney Center at Sesame Workshop. Retrieved from http://www.joanganzcooneycenter.org/Reports-35.html 
Chiong, C., \& Shuler, C. (2010). Learning: Is there an app for that? Investigations of young children's usage and learning with mobile devices and apps. New York, NY: The Joan Ganz Cooney Center at Sesame Workshop. Retrieved from http://www-tc.pbskids.org/read/files/cooney learning apps.pdf

Clements, D. H., \& Sarama, J. (2003). Strip mining for gold: Research and policy in educational technology: A response to "Fool's Gold." Educational Technology Review, 11(1), 7-69. Retrieved from https://www.aace.org/pubs/etr/issue4/clements2.pdf

Cohen, J. (1992). A power primer. Psychological Bulletin, 112(1), 155-159.

Cohen, M., Hadley, M., \& Frank, M. (2011). Young children, apps \& Ipad. New York, NY: Michael Cohen Group. Retrieved from http://mcgroup.wpengine.com/wp-content/uploads/2015/03/ipad-study-coverpage-report-mcg-info_new-online.pdf

Daugherty, L., Dossani, R., Johnson, E. E., \& Wright, C. (2014). Getting on the same page: Identifying goals for technology use in early childhood education. Santa Monica, CA: RAND Corporation. Retrieved from http://www.rand.org/content/dam/rand/pubs/research_reports/RR600/RR673z1/RAND_RR673z1.pdf

DeCurtis, L. L., \& Ferrer, D. (2011, September). Toddlers and technology: Teaching the techniques. The ASHA Leader, 16. Retrieved from http://leader.pubs.asha.org/article.aspx?articleid=2280052

Duncan, G. J., \& Magnuson, K. A. (2005). Can family socioeconomic resources account for racial and ethnic test score gaps? The Future of Children, 15(1), 35-54. Retrieved from http://futureofchildren.org/publications/journals/article/index.xml?journalid=38\&articleid=115\&sectio $\underline{\text { nid }=745}$

Early, D., Barbarin, O., Bryant, D., Burchinal, M., Chang, F., Clifford, R., ... Weaver, W. (2005). Prekindergarten in eleven states: NCEDL's multi-state study of pre-kindergarten and state-wide early educational programs (SWEEP) study. Chapel Hill, NC: Frank Porter Graham Child Development Institute. Retrieved from http://fpg.unc.edu/sites/fpg.unc.edu/files/resources/reports-and-policybriefs/NCEDL PreK-in-Eleven-States Working-Paper_2005.pdf

Gillani, B. B. (2003). Learning theories and the design of e-learning environments. Lanham, MD: University Press of America.

Glaubke, C. R. (2007). The effects of interactive media on preschoolers' learning: A review of the research and recommendations for the future. Oakland, CA: Children Now. Retrieved from http://s78640.gridserver.com/uploads/documents/prek_interactive_learning_2007.pdf

Goodwin, K. (2008). The impact of interactive multi-media on kindergarten students' representations of fractions. Issues in Educational Research, 18(2), 103-117. Retrieved from http://www.iier.org.au/iier18/goodwin.pdf

Guernsey, L., Levine, M., Chiong, C., \& Severns, M. (2012). Pioneering literacy in the digital Wild West: Empowering parents and educators. New York, NY: The Joan Ganz Cooney Center at Sesame Workshop. Retrieved from http://www.joanganzcooneycenter.org/wpcontent/uploads/2012/12/GLR_TechnologyGuide_final.pdf

Hamre, B. K., \& Pianta, R. C. (2007). Learning opportunities in preschool and early elementary classrooms. In R. C. Pianta, M. J. Cox, \& K. L. Snow (Eds.), School readiness \& the transition to kindergarten in the era of accountability (pp. 49-83). Baltimore, MD: Paul H. Brookes Publishing Co.

Hirsh-Pasek, K., Zosh, J. M., Golinkoff, R. M., Gray, J. H., Robb, M. B., \& Kaufman, J. K. (2015). Putting education in "educational" apps: Lessons from the science of learning. Psychological Science in the Public Interest, 16(1), 3-34. Retrieved from http://psi.sagepub.com/content/16/1/3.full.pdf + html?ijkey=GxHiSvddIDi.E\&keytype=ref\&siteid=sppsi $\% 2520$

Hourcade, J. P., Bederson, B. B., Druin, A., \& Guimbretiére, F. (2004). Differences in pointing task performance between preschool children and adults using mice. ACM Transactions on Computer-Human Interaction, 11(4), 357-386. 
Jordan, N. C., Kaplan, D., Locuniak, M. N., \& Ramineni, C. (2007). Predicting first grade math achievement from developmental number sense trajectories. Learning Disabilities Research and Practice, 22(1), 36-46.

Jordan, N. C., Kaplan, D., Nabors-Oláh, L., \& Locuniak, M. N. (2006). Number sense growth in kindergarten: A longitudinal investigation of children at risk for mathematical difficulties. Child Development, 77(1), 153-175.

Karoly, L. A., Kilburn, M. R., \& Cannon, J. S. (2005). Early childhood intervention: Proven results, future promise. Santa Monica, CA: RAND Corporation. Retrieved from http://www.rand.org/content/dam/rand/pubs/monographs/2005/RAND_MG341.pdf

Kent, P. (2004, July). E-teaching and interactive whiteboards: Technology used to enhance effective pedagogy-Creating a significant impact on classroom practice and student learning. Paper presented at the Australian Computers in Education Conference, Adelaide. Retrieved from http://www.teachade.com/resources/support/5031af3af10a7.pdf

Lacour, M., \& Tissington, L. D. (2011). The effects of poverty on academic achievement. Educational Research and Reviews, 6(7), 522-527. Retrieved from http://www.academicjournals.org/article/article1379765941_Lacour\%20and\%20Tissington.pdf

Levin, D. E. (2011). Beyond remote-controlled teaching and learning: The special challenges of helping children construct knowledge today. Exchange, May/June.

Linn, S., Almon, J. W., \& Levin, D. E. (2012). Facing the screen dilemma: Young children, technology, and early education. Boston, MA: Campaign for a Commercial-Free Childhood, and New York, NY: Alliance for Childhood,. Retrieved from http://www.commercialfreechildhood.org/sites/default/files/facingthescreendilemma.pdf

Localystics. (2011, January). First impressions matter! 26\% of apps downloaded in 2010 were used just once. Retrieved from http://info.localytics.com/blog/first-impressions-26-percent-of-apps-downloadedused-just-once

Lonigan, C., Wagner, R., Torgesen, J., \& Rashotte, C. (2007). The Test of Preschool Early Literacy (TOPEL). Austin, TX: PRO-ED.

Lourenço, O. (2012). Piaget and Vygotsky: Many resemblances, and a crucial difference. New Ideas in Psychology, 30(3), 281-295. Retrieved from http://www.sciencedirect.com/science/article/pii/S0732118X1100078X

Mattingly, M. J., Johnson, K. M., \& Schaefer, A. (2011). More poor kids in more poor places: Children increasingly live where poverty persists: Issue brief 38. Durham, NH: Carsey Institute University of New Hampshire. Retrieved from http://scholars.unh.edu/cgi/viewcontent.cgi?article $=1149 \&$ context $=$ carsey

McCarrick, K., \& Xiaoming, L. (2007). Buried treasure: The impact of computer use on young children's social, cognitive, language development and motivation. AACE Journal, 15(1), 73-95. Retrieved from http://www.editlib.org/results/?q=Buried+treasure\&source=AACEJ

McManis, L. D., Gunnewig, S. B., \& McManis, M. H. (2010). Exploring the contribution of a contentinfused interactive whiteboard for school readiness. (ED528703) Retrieved from http://files.eric.ed.gov/fulltext/ED528703.pdf

McManis, L. D., \& Gunnewig, S. B. (2012). Finding the education in educational technology with early learners. Young Children, 67(3), 14-25. Retrieved from http://www.naeyc.org/yc/files/yc/file/201205/McManis_YC0512.pdf

McManis, P. W., \& McManis, M. H. (2016). Validating the hierarchy of the iStartSmart academic content. (ED565861) Retrieved from http://files.eric.ed.gov/fulltext/ED565861.pdf

NACCRRA. (2013). State minimum education requirements for child care center directors and lead teachers. Arlington, VA: National Association of Child Care Resource and Referral Agencies. Retrieved from http://www.naccrra.net/about-child-care/state-child-care-licensing/training-requirements 
National Association for the Education of Young Children \& Fred Rogers Center for Early Learning and Children's Media. (2012). Technology and interactive media as tools in early childhood programs serving children from birth through age 8 . Retrieved from http://www.naeyc.org/files/naeyc/file/positions/PS_technology_WEB2.pdf

National Early Literacy Panel. (2008). Developing early literacy: Report of the National Early Literacy Panel. Washington, DC: National Institute for Literacy. Retrieved from http://lincs.ed.gov/publications/pdf/NELPReport09.pdf

National Research Council Committee on Early Childhood Mathematics. (2009). C. T. Cross, T. A. Woods, $\&$ H. Schweingruber (Eds.). Mathematics learning in early childhood: Paths toward excellence and equity. Washington, DC: National Research Council and National Academy of Sciences.

Neumann, M. M., \& Neumann, D. L. (2014). Touch screen tablets and emergent literacy. Early Childhood Education Journal, 42(4), 231-239.

Nores, M., \& Barnett, W. S. (2014). Access to high quality care and education: Readiness and opportunity gaps in America. New Brunswick, NJ: CEELO (Center for Enhancing Early Learning Outcomes) \& NIEER (National Institute for Early Education Research). Retrieved from http://ceelo.org/wpcontent/uploads/2014/05/ceelo_policy_report access_quality_ece.pdf

Pasnik, S., \& Llorente, C. (2013). Preschool teachers can use a PBS Kids transmedia curriculum supplement to support young children's mathematics learning: Results of a randomized controlled trial. A report to the CPB-PBS Ready to Learn Initiative. Waltham, MA: Education Development Center, and Menlo Park, CA: SRI International. Retrieved from https://www.sri.com/sites/default/files/publications/ready-to-learn-transmedia-math-report-nov2013.pdf

Penuel, W. R., Pasnik, S., Bates, L., Townsend, E., Gallagher, L. P., Llorente, C., \& Hupert, N. (2009). Preschool teachers can use a media-rich curriculum to prepare low-income children for school success: Results of a randomized controlled trial. New York, NY: Education Development Center, and Menlo Park, CA: SRI International. Retrieved from http://cct.edc.org/sites/cct.edc.org/files/publications/RTLSummativeEvalReport.pdf

Reynolds, A. J., Temple, J. A., Ou, S., Arteaga, I. A., \& White, B. A. (2011). School-based early childhood education and age-28 well-being: Effects by timing, dosage, and subgroups. Science, 333(6040), 360364.

Rideout, V. J. \& Katz, V. S. (2016). Opportunity for all? Technology and learning in lower-income families. A report of the Families and Media Project. New York, NY: The Joan Ganz Cooney Center at Sesame Workshop. Retrieved from http://www.joanganzcooneycenter.org/wpcontent/uploads/2016/01/jgcc_opportunityforall.pdf

Schneider, W. (2008). The development of metacognitive knowledge in children and adolescents: Major trends and implications for education. Mind, Brain, and Education, 2(3), 114-121.

Shuler, C. (2012). iLearnII; An analysis of the education category of the iTunes App Store. New York, NY: The Joan Ganz Cooney Center at Sesame Workshop. Retrieved from http://www.joanganzcooneycenter.org/wp-content/uploads/2012/01/ilearnii.pdf

Simon, F., Nemeth, K., \& McManis, L. D. (2013). Technology in ECE classrooms: Results of a new survey and implications for the field. Exchange Magazine, 35(5), 68-75.

Sluis, R. J. W., Weevers, I., Van Schijndel, C. H. G. J., Kolos-Mazuryk, L., Fitrianie, S., \& Martens, J. B. O. S. (2004, June). Read-It: Five-to-seven-year-old children learn to read in a tabletop environment. Proceedings of the International Conference on Interaction Design and Children, College Park, MD. Retrieved from http://mmi.tudelft.nl/pub/siska/IDC\%20read-it.pdf

Subrahmanyam, K., \& Greenfield, P. (2008). Media symbol systems and cognitive processes. In S. L. Calvert, \& B. J. Wilson (Eds.), The handbook of children, media, and development (pp. 166-87). Hoboken, NJ: Wiley-Blackwell. 
Teaching Strategies. (2015, September). Early childhood technology survey. Bethesda, MA: Author. Retrieved from http://teachingstrategies.com/wp-content/uploads/2016/03/Tech-Survey-FindingsSummary-FINAL-002.pdf

Torgerson, C. J., \& Zhu, D. (2004). A systematic review and meta-analysis of the effectiveness of ICT on literacy learning in English. The impact of ICT on literacy education, 5-16. London, UK: Andrews, R. Routledge/Falmer.

Vaala, S., Ly, A., \& Levine, M. H. (2015). Getting a read on the app stores: A market scan and analysis of children's literacy apps. New York, NY: The Joan Ganz Cooney Center at Sesame Workshop. Retrieved from http://www.joanganzcooneycenter.org/wp-content/uploads/2015/12/jgcc_gettingaread.pdf

Vernadakis, N., Avgerinos, A., Tsitskari, E., \& Zachopoulou, E. (2005). The use of computer assisted instruction in preschool education: Making teaching meaningful. Early Childhood Education Journal, 33(2), 99-104.

Whitehurst, G. (2003, April). The Institute of Education Science: New wine and new bottle. Presentation at the annual meeting of the American Educational Research Association, Chicago, IL. (ED 478983) Retrieved from http://files.eric.ed.gov/fulltext/ED478983.pdf

\section{Biographies}

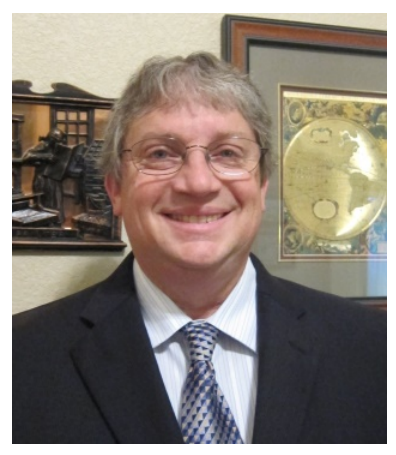

Mark H. McManis is a Research Associate Professor at the University of Texas at Austin in the Department of Psychology. He earned his $\mathrm{PhD}$ in Developmental Psychology at the University of Florida with a concentration in statistics. He pursued postdoctoral training at Harvard University and the University of Texas at Houston where he studied cognitive and emotional processes in children. His specialty is cognitive neuroscience and functional neuroimaging. Over the past two decades he has conducted numerous studies of cognitive development and how the brain works in children with neurocognitive deficits.

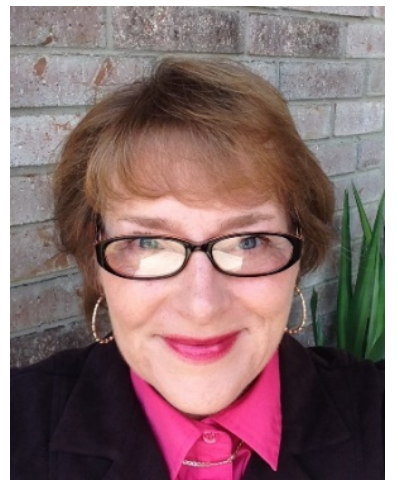

Lilla Dale McManis holds a $\mathrm{PhD}$ in educational psychology with a concentration in learning and cognition from the University of Florida. For the past thirty years she has worked with at-risk youth as a special education teacher, program evaluator, and researcher. She is currently President and CEO of Early Childhood Research Solutions, an independent consulting firm based in Austin, Texas specializing in assessment, program improvement, and working with start-ups to translate research into practice. She is a founding member of the Early Childhood Technology Collaborative and has a particular interest in the role of technology in promoting school readiness for under-resourced children. 